\title{
A STUDY OF THE SEDIMENTATION RATE IN JUVENILE RHEUMATISM
}

\author{
BY
}

W. W. PAYNE, M.B., and BERNARD SCHLESINGER, M.D., F.R.C.P.*

(From the Hospital for Sick Children, Great Ormond Street and the I.C.A.A. Children's Heart Hospital, West Wickham.)

In a previous communication ${ }^{3}$ a simple method of estimating the sedimentation rate (S.R.) was described which had the great advantage of requiring only a finger prick. Close agreement between the degree of rheumatic activity and the height of the sedimentation rate was demonstrated. This has been confirmed by Bach and Gray Hill ${ }^{1}$, Struthers and Bacal $^{6}$, Perry ${ }^{4}$ and others. In this paper it is proposed to record experiences in a larger series of cases, mostly patients at the Children's Heart Hospital, West Wickham, and coming under observation for varying periods from a few months to three years. The behaviour of the sedimenta tion rate in this larger series confirms the conclusions of the origina' investigation. Certain exceptions, however, were encountered which are no: easy to explain and might well give rise to occasional difficulty in the interpretation of the test. Reference to these forms an important part of the present communication.

The sedimentation rate in relation to the rheumatic state.

The patients were divided into active and non-active cases, a clinical grouping which was made without reference to the result of the sedimentation rate. The criteria of activity have been pulse rate, temperature, weight and cardiac signs. In doubtful cases the electro-cardiograph was occasionally employed. From the outset it was recognized that other conditions can produce an increased sedimentation rate and allowance has been made for a transient rise due to intercurrent infections such as common colds, influenza, tonsillitis and otitis media. The normal sedimentation rate is between 3-10 mm., but here it has not been considered abnormal unless it exceeded $14 \mathrm{~mm}$. The following is a brief summary of the results obtained in two hundred and twenty-nine children. The number of observations on each patient averaged seven; occasionally the test was only performed once, but in some it was repeated as often as twenty times.

Non-active cases. There were one hundred and forty children with no evidence of active rheumatism during the period of observation. Seventyfour of these had no signs of cardiac involvement and, with three exceptions, showed no rise in the sedimentation rate apart from intercurrent infections. There was no apparent reason for the raised values $(17,21$ and $29 \mathrm{~mm}$. maximum) in the three cases, except for tonsillar sepsis in one instance.

\footnotetext{
* Working with a grant from the Harmsworth Research Fund.
} 
Sixty-six children had had heart disease at some time or other. The sedimentation rate was normal in fifty-six and raised in ten. In five this rise was transitory.

Active cases. Active rheumatism was present in eighty-nine cases. Sixty-six showed rapid improvement and were finally considered no longer active from the clinical standpoint. The sedimentation rate showed a corresponding fall to normal in fifty-eight. In seven the sedimentation rate was higher or lower than was to be expected, and in one apparently quiescent case a fresh rise in the sedimentation rate appeared to herald a re-awakened activity with chorea sometime after returning home.

In sixteen cases the activity was marked and prolonged. Here without exception the sedimentation rate was raised in close agreement with the clinical condition (cf. Payne ${ }^{3}$ ).

Seven fatal cases occurred. All but one showed a raised sedimentation rate, but curiously enough not so high as in many of the acute cases which recovered. In the one case with normal values cardiac failure was prominent (see p. 409). Hence with every type of rheumatism there is close agreement between the S.R. and the clinical picture and this has been confirmed in many cases in this series by the subsequent history. In fact, in only twenty out of the whole two hundred and twenty-nine cases was there any discrepancy.*

From these results, therefore, it appears justified to regard the S.R. as a valuable test which allows observation of the progress of rheumatic children to be made with great accuracy. Those who make use of it, however, must not forget that many other conditions besides active rheumatism may increase the sedimentation rate. Any acute fever or inflammatory lesion may do this, but it has been repeatedly noticed in the course of the present investigations that the common cold without complications appears not to affect it.

\section{The influence of other disorders on the sedimentation rate.}

Acute tonsillitis or naso-pharyngitis generally produces a rise in the S.R. (20-40 mm.) lasting two or three weeks, after which as a rule it drops to normal. A relapse or some other complication such as otitis or adenitis will delay this. Acute throat infections associated with influenza, on the other hand, behave differently, and the S.R. even in the absence of complications often takes a long time to settle. This is of distinct clinical interest and reflects the latent severity of this infection.

The picture is complicated when either of these acute infections occurs in a rheumatic subject, and the duration of the raised S.R. will largely depend on the previous rheumatic state. Patients with non-active rheumatism will react like normal individuals to acute tonsillitis, the S.R. remaining raised for about two weeks only. A more prolonged disturbance of the S.R. (3-4 weeks) must be expected after tonsillitis in actively rheumatic patients and when a fresh wave of acute rheumatism follows, high S.R. figures continue for months. These points are illustrated

* In nine this could be almost discounted on the grounds that the reading was above normal on one occasion only. 
in table 1 , and when studying this it should be borne in mind that a relapse of rheumatism is more likely to follow tonsillitis than influenza.

TABLE 1.

\begin{tabular}{|c|c|c|c|c|c|c|}
\hline \multirow{2}{*}{ Cases. } & \multicolumn{4}{|c|}{ DuRation IN WEeks. } & \multirow{2}{*}{\multicolumn{2}{|c|}{$\begin{array}{c}\text { Total NUMBER } \\
\text { OF CASES. }\end{array}$}} \\
\hline & 0-2 & $3-5$ & $6-8$ & over 8 & & \\
\hline \multicolumn{7}{|c|}{$\begin{array}{l}\text { NON-ACTIVE } \\
\text { RHEUMATISM }\end{array}$} \\
\hline INFLUENZA & 5 & 8 & 1 & 1 & & 15 \\
\hline Tonsillitis & 7 & $\mathbf{3}$ & $\mathbf{0}$ & $\mathbf{0}$ & & 10 \\
\hline $\begin{array}{l}\text { Active } \\
\text { RHEUMATIS }\end{array}$ & & & & & & . \\
\hline INFLUENZA & $\mathbf{0}$ & 5 & $\mathbf{0}$ & $\mathbf{1}$ & & 6 \\
\hline TonsILLITIS & $\mathbf{0}$ & 5 & 6 & 4 & & 15 \\
\hline
\end{tabular}

To show the duration of increased S.R. in weeks following attacks of influenza or tonsillitis in rheumatic children.

Chronic tonsillar sepsis.-..The importance of this has been fully recognized and an endeavour was made to see if the S.R. was affected. Mr. James Crooks, F.R.C.S., has kindly allowed reference to a series of children under his supervision who were suffering from definite tonsillar sepsis requiring operation. Among thirty-eight non-rheumatic cases, fourteen had values above $14 \mathrm{~mm}$. at one time or another before operation, but only in seven was this a constant feature on the two or three occasions when the test was repeated. Thus it will be seen that with occasional striking exceptions chronic tonsillar sepsis on the whole does not affect the S.R.

Tuberculosis. - A raised S.R. and failure to gain weight may also be the only obvious indication of this infection. In one young boy of six years, wrongly suspected of rheumatic carditis, the reason for a persistent high S.R. remained puzzling until a positive Mantoux test and radiographic evidence of large glands at the hilum revealed the true cause.

Rheumatoid arthritis.-When large numbers of rheumatic children are under supervision the rare inclusion of a case of rheumatoid arthritis in its earliest stages is apt to be misleading. A patient with this malady caused confusion for some time and an early active rheumatic carditis was expected in view of the history of fleeting joint pains, tachycardia, stationary weight and a considerable rise in the S.R. It was only later with the onset of the 
characteristic thickening of the joint capsules and limitation of movement that the nature of the illness became clear.

Effect of anaemia.-It is generally recognized that anaemia has an effect on the S.R. Walton ${ }^{7}$ has therefore suggested that the ideal method of performing the test would be first to bring the blood to a normal red count by removing a calculated amount of plasma from the centrifugalized blood, to suspend the red blood cells again in the remaining plasma and then to determine the S.R. This process is too cumbersome for routine use in a large number of cases and also has the additional disadvantage of requiring venu-puncture. While experimenting with this method, Walton also found that when specimens of blood obtained from different cases were diluted with their corresponding blood plasma until a red cell count of 1,000,000 per c.mm. had been reached, approximately the same S.R. reading $\left(27.5 \mathrm{~mm} .{ }^{*}\right)$ was obtained, irrespective of what it had been originally. In other words, under the experimental condition of extreme dilution of the red blood cells relatively little difference was to be found between normal and pathological cases. Using $27.5 \mathrm{~mm}$. as a constant standard figure for a red cell count of $1,000,000$, Walton constructed a graph showing the variations in the S.R. in relation to the different dilutions of the red blood cells. The curve obtained almost described a straight line and it was claimed that from this a corrected S.R. figure could be estimated in any case, taking into account the degree of anaemia present.

An attempt was made to apply these observations to the method employed in testing the S.R. The experiments are illustrated in fig. 1 A and B

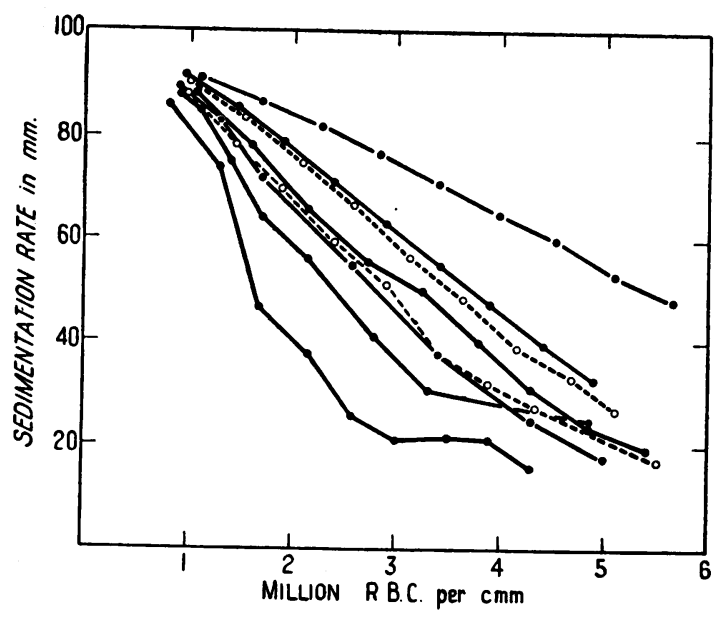

$\mathbf{1 A}$

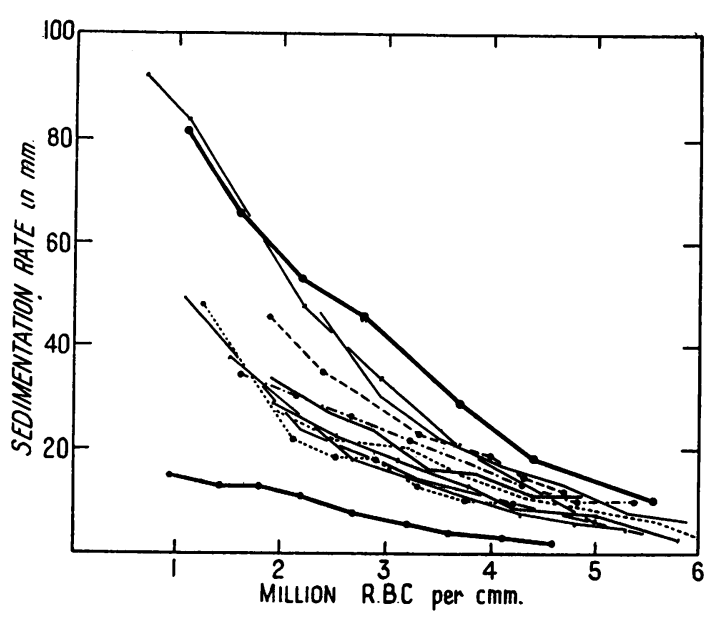

1B

FIg. 1.- To show the effect on the S.R. of diluting blood with its own plasma. "Artificial anaemia." The R.B.C. count indicates the degree of dilution.

A. 8 subjects with high sedimentation rates.

B. 12 subjects with normal sedimentation rates.

* Owing to the difference in technique this corresponds to a value of about 85-90 mm. in our method. 
and do not confirm Walton's findings. The value of the S.R. with the red cells diluted to $1,000,000$ per c.mm. was by no means constant, varying in patients with active rheumatism between 81 and $92 \mathrm{~mm}$. and in a group of healthy, normal controls, between 15 and $86 \mathrm{~mm}$. Furthermore, although in some cases the plotted readings of the S.R. in relation to different red cell counts were found to describe a straight line on a graph, this was not the rule. The S.R. readings gave the most divergent results in the region of 3 to 5 million, where the red blood cell count would naturally fall in the majority of cases.

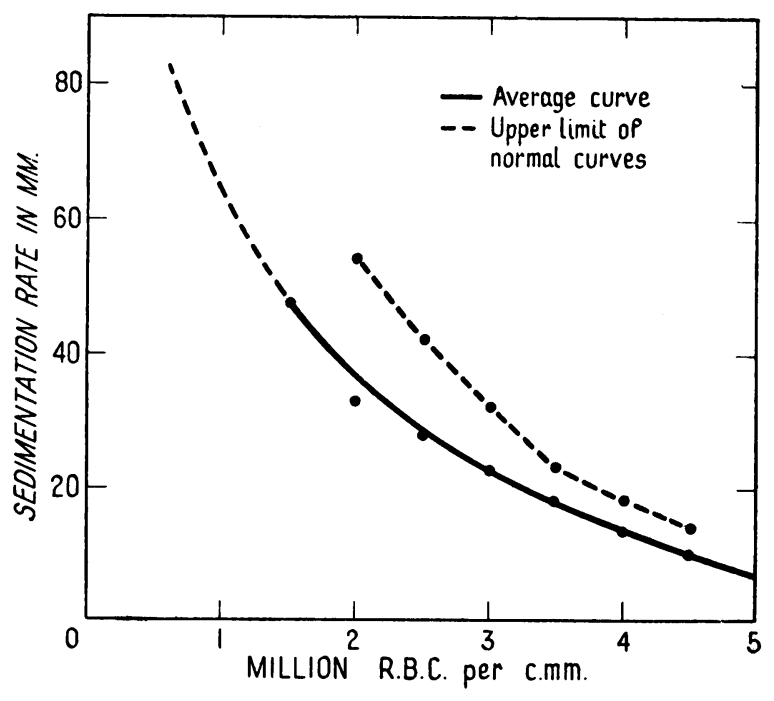

FIg. 2.-To show the average and maximal values of the S.R. in normal subjects at various R.B.C. counts.

Wintrobe and Lansberg ${ }^{9}$ have obtained similar curves to those here described. They constructed an average curve from them and a chart which enabled the correction for the cell count to be read for any given sedimentation reading. A S.R. value calculated in this manner showed wide variation in many cases from that obtained by direct reading, after the blood had been artificially adjusted to a normal cell count.

In the absence of any accurate method of making corrections for anaemia a graph has been constructed, fig. 2, showing the average normal value of the S.R. at any known red cell count. The S.R. reading obtained in a given case is compared with the figure on the graph at the corresponding 
red cell count. If the former is higher it may be assumed that the S.R. is increased apart from any effect due to anaemia.

Chorea.-In the course of this work it has been found that the S.R. is not affected in the same manner by chorea as it is by other forms of active rheumatism. Fifty cases were investigated in which chorea was the salient feature, although in some instances it was associated with other manifestations of acute rheumatism. With only a few exceptions the patients were kept under observations for at least six months after the chorea had subsided. It soon became apparent that the close parallelism between the height of the S.R. and the degree of active disease present, which has already been noted in various forms of acute rheumatism, does not hold good in regard to chorea. In twenty-eight of these fifty cases the S.R. remained raised for a short time only after admission to hospital, and in twenty-two it was never above normal. Many of the S.R. figures obtained were in fact, abnormally low, readings of 3,2 or even $1 \mathrm{~mm}$. being relatively common. This appeared to be such a striking feature in children subject to chorea that it was questioned whether or not S.R. values of $10-14 \mathrm{~mm}$., generally regarded as normal, should be considered in chorea a sign of active disease. Seven patients developed chorea whilst under observation. In three the onset of the condition caused no increase in the S.R. and in the other four the rise was only transitory, the figures obtained being 15, 15, 18, and $45 \mathrm{~mm}$. respectively.

Perry $^{4}$, Warner ${ }^{8}$, and Struthers and Bacal ${ }^{6}$ have all commented on the slight effect of acute chorea on the sedimentation rate. In their reports even less deviation from the normal was discovered than in the present series of cases. On the whole the present results lead to the belief that chorea generally produces a slight alteration in the S.R. It was hoped that the test would enable cases of chorea to be picked out which would be likely to develop cardiac disease, a high S.R. giving an indication that this might happen and vice versa. The same group of fifty cases was therefore studied in regard to this. The results were as follows and demonstrate that no reliance can be placed on the S.R. in this respect:-

S.R. DURING CHOREA.

$\begin{array}{lll}\text { NoRMAL } \ldots & \ldots & \\ \text { BETWEEN 14-20 MM. } & \ldots & \ldots \\ \text { OvER } 20 \text { MM. } & \ldots & \ldots\end{array}$
Evidence OF FRESH CARDIAC DISEASE. Absent. Present.

In conducting these investigations it was difficult to exclude with certainty one possible fallacy. Unless a patient is under almost continuous observation, detection of heart disease for the first time six to twelve months after an attack of chorea does not necessarily mean that the one is the direct outcome of the other. As is emphasized elsewhere in this paper mild attacks of rheumatic fever may pass unnoticed. Such an attack during the intervening twelve months, and not the chorea as observed, might easily have been the true origin of the fresh cardiac involvement. Two of the 
six cases which developed carditis were under such constant supervision that the heart disease could definitely be attributed to the chorea. In these two cases the S.R. tested at the time of the chorea and repeatedly examined during the subsequent months never rose above normal.

Congestive failure.-Cardiac failure has a curious effect on the S.R. However active the rheumatic process may be, the onset of congestive failure and oedema causes the S.R. to fall from its previous high figure. The fall may continue to a level which in any other circumstances would be considered normal. Hässler and Möller ${ }^{2}$, Struthers ${ }^{6}$, and Perry ${ }^{4}$ have all recorded such cases, and the phenomenon has been observed by us in at least eight patients (fig. 3). The fall of the S.R. may occur before any definite signs of failure are noticed, and at the time of the observation in one case there was even an apparent clinical improvement. Undoubtedly the fall often precedes the appearance of oedema, and it is believed that it occurs approximately at the time of hepatic enlargement. The converse of the same phenomenon was also observed. In three cases of severe active rheumatism the S.R. had fallen in the manner described with the onset of congestive failure. The clinical condition gradually improved under treatment, the oedema subsided and the S.R. rose above normal again. One patient ultimately recovered and the S.R. slowly returned to normal, proving this time that the rheumatic process had ceased to be active. Such a case is the exception and as all the remaining patients in this group died, a fall of the S.R. without clinical improvement or subsidence of rheumatic activity must be regarded as a bad prognostic sign. The cause of these effects is not known, but since it is generally assumed that the most important single factor influencing the S.R. lies in the composition of the plasma proteins, in particular the fibrin, analysis of the blood plasma was made in two cases. The results obtained were as follows:-

\begin{tabular}{|c|c|c|c|c|c|c|c|c|c|}
\hline Plasma & PROTEINS. & Cas & E D. & CAs & SE $\mathbf{S}$. & & & JoRn & IAL. \\
\hline Albumin & ... & 3.25 PER & CENT. & 3.00 PER & CENT & & $4 \cdot 4$ & PER & CENT. \\
\hline GLOBULIN & $\cdots$ & 1.99, & , & $2 \cdot 44$, & ,' & & $2 \cdot 1$ & , & , \\
\hline Fibrin & $\cdots \quad \cdots$ & $\mathbf{0} \cdot \mathbf{3 0}$, & ,' & 0.43, & , & & $0 \cdot 3$ & , & , \\
\hline $\begin{array}{l}\text { Blood col } \\
\text { SEDIMENTA } \\
\text { CorRECTED }\end{array}$ & $\begin{array}{l}\text { UN', R.B.C. } \\
\text { ATION RATE } \\
\text { D.R. FOR }\end{array}$ & $\begin{array}{l}4,300,000 \\
5\end{array}$ & PER C.MM. & $\begin{array}{l}3,710,000 \\
21\end{array}$ & PER & C.MM. & & (2) & 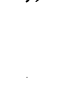 \\
\hline $5,000,000$ & 0 R.B.C. ... & 4 & & 6 & & & & & \\
\hline
\end{tabular}

Judging from the experience of others (Rourke and Ernstene ${ }^{5}$ ) in acute rheumatism, and from our unpublished observations in active rheumatoid arthritis with a raised S.R., the plasma fibrin content and the albuminglobulin ratio in case $\mathbf{D}$ are much nearer the normal than is usually found. Had these chemical changes in the blood also been present in case $\mathbf{S}$ in association with cardiac failure, they might have accounted for the spurious fall of the S.R. but in case $S$ the values obtained are such as would lead one to expect a high S.R. It appears from these two isolated investigations that the explanation may have to be sought elsewhere, 
Discussion.

Those who make use of the test in regard to rheumatism must understand that it is in no way specific. Nearly all pyrexial infections are followed by a high sedimentation rate and inflammatory lesions unaccompanied by a rise in temperature may also behave in the same way. It is a most useful and sensitive method of estimating the degree of active rheumatism present, but it would be misleading to place complete reliance on it to the exclusion of all other criteria. Due regard must also be paid to the patient's general condition, the sleeping pulse rate, the physical signs present and the temperature and weight charts. A single high reading should not be trusted, but a constant high S.R. suggests an active rheumatic state.

Obvious rheumatic fever or active carditis, the latter often apyrexial, is pre-eminently characterized by a raised S.R. In the acute phase the test is almost superfluous, but later during convalescence it serves as a useful guide as to when the patient can be allowed to get up.

Miniature rheumatic fever.- The test has the greatest value following tonsillitis, since it is in this connection with such acute infections that rheumatic relapses are most often expected. Every degree of relapse has been observed, varying from an acute and virulent pericarditis with early death to the mildest forms of rheumatic fever. The latter has been termed by the authors ' miniature rheumatic fever.' It is characterized by slight degrees of fever, transient tachycardia and a persistent or fresh rise in the S.R. following the subsidence of the throat infection. The slightest cases produce no changes in the temperature or pulse rate and only affect the S.R. Otherwise they would pass unnoticed. They are of some interest in showing the latent tendency to relapse after tonsillitis although fortunately in most instances the patient's defences are able to overcome this (see fig. 4).

Sub-acute rheumatism.-The S.R. is a considerable help in indicating the line of treatment in sub-acute rheumatism, particularly as some authorities have begun to question the importance of 'growing pains' in all instances. The present investigation indicates that a normal S.R. in such cases justifies the belief that the heart is in no danger and therefore allows less rigorous therapeutic measures. In old rheumatic cases a temporary rise in the S.R. has been repeatedly observed with the return of subacute pains in the limbs. Generally the temperature is hardly affected, if at all, and the whole affair is over in a few days. There may already be heart disease present in these sub-acute rheumatic cases, dating from a previous acute attack, and the question then arises whether there is any fresh cardiac involvement. In the absence of any clinical signs of this, the S.R. furnishes the best answer, and if it is normal there is no indication for drastic precautions.

Chorea, and its influence on the S.R., has already been discussed in some detail. It is curious that the S.R. may be little affected in the most acute cases, whereas it may be appreciably raised in mild degrees of chorea. There is no means of foretelling what to expect. Certainly a normal S.R. in chorea does not preclude heart disease developing soon afterwards, 


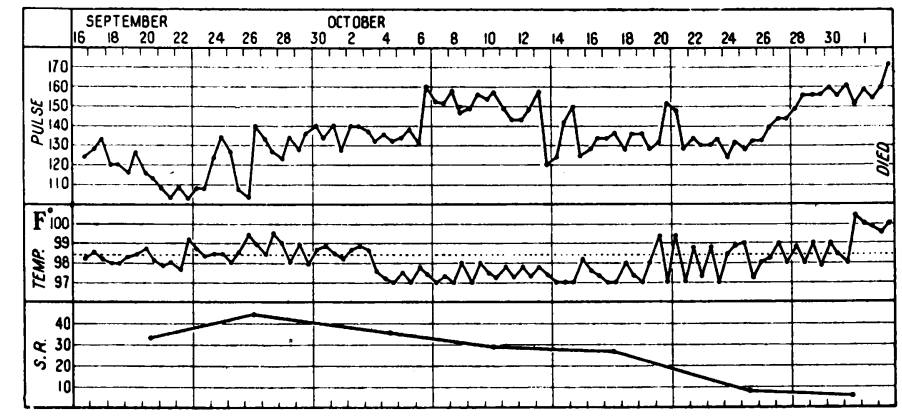

D. M., age 3 yr. Cardiac disease.

Frg. 3. (Case D.).-To show the fall of the S.R. with onset of congestive cardiac failure.

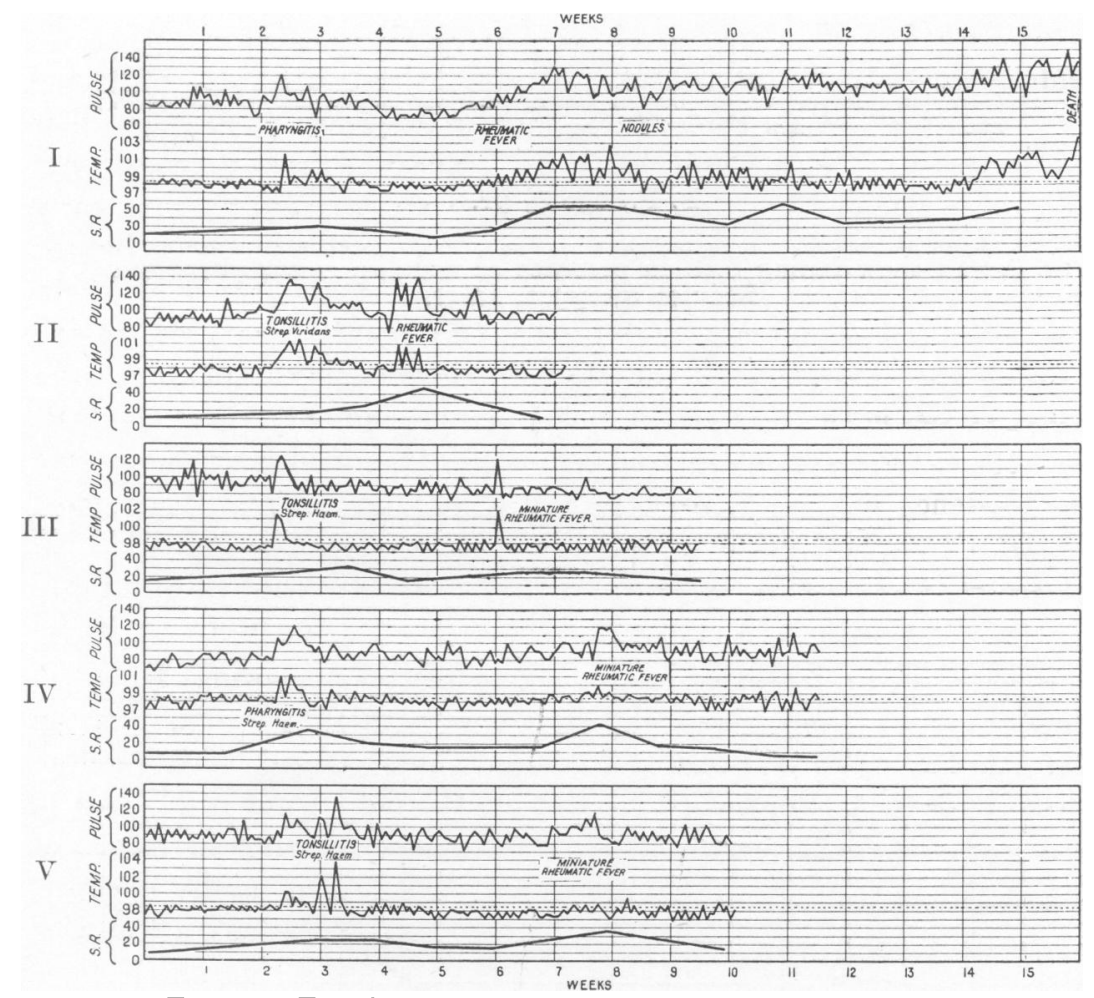

FIG. 4.-To show response after silent period to acute naso-pharyngeal infection in varying degree of severity.

I. Rheumatic fever, pericarditis, nodules with fatal result.

II. Rheumatic fever. Rise in pulse, temperature, S.R.

III. 'Miniature rheumatic fever.' Transient rise in temperature and pulse. Rise in S.R. of longer duration.

IV. 'Miniature rheumatic fever.' Rise in pulse rate, negligible rise of temperature. Definite rise of S.R.

V. 'Miniature rheumatic fever.' Slight rise in pulse rate, no rise of temperature. Definite rise of S.R. 


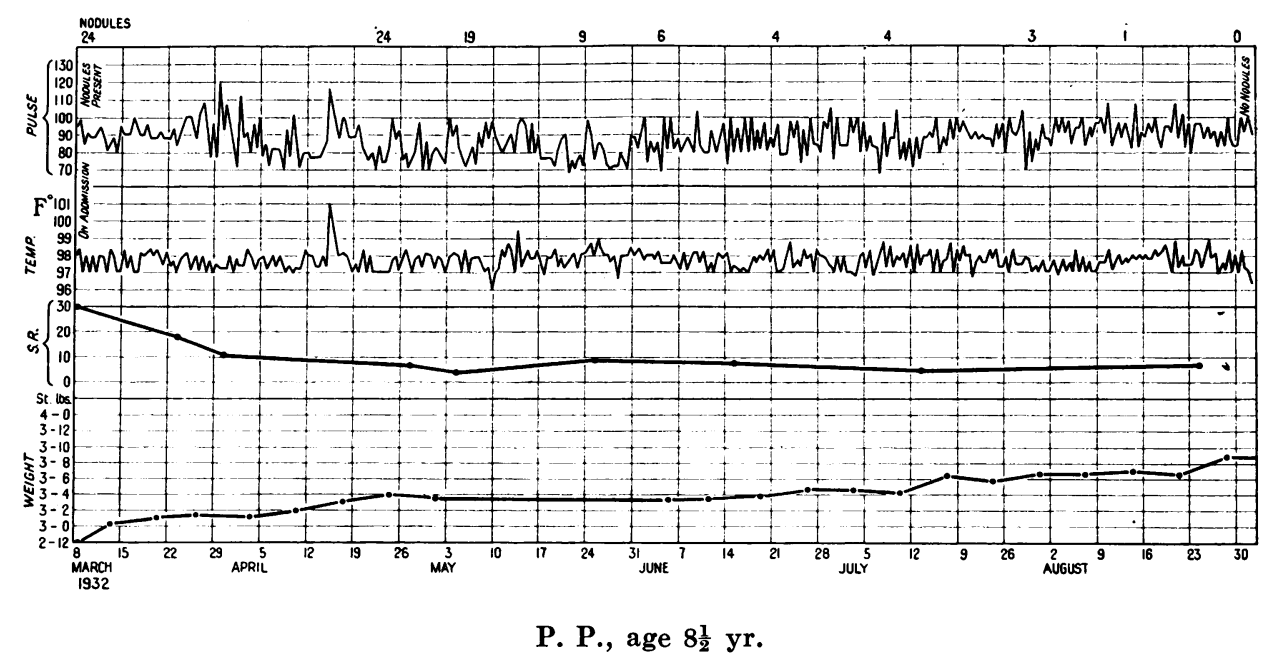

FIG. 5.-To show falling S.R. in presence of nodules, active phase over, nodules disappear later.

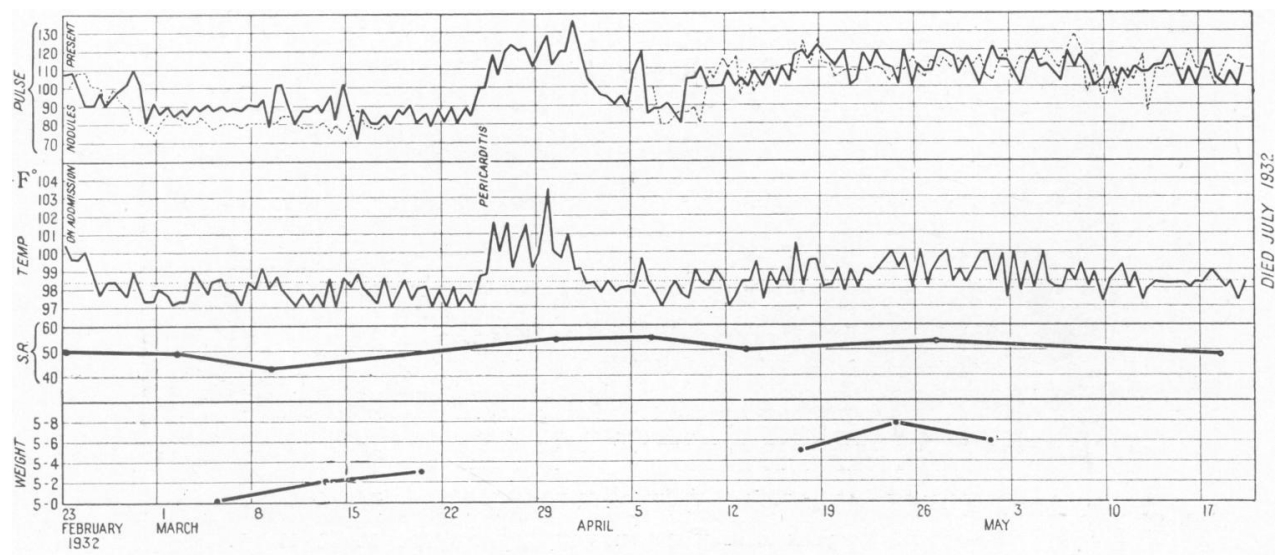

I. E., age $12 \frac{1}{2}$ yr.

Fig. 6.-Persistent raised S.R. in presence of nodules, active disease still present: terminated in death, 
Nodules.-The test is of considerable prognostic value when subcutaneous nodules are present. There is generally an appreciable lag in the time these appear and disappear in relation to the other active rheumatic manifestations. It is therefore somewhat difficult to decide what stage the disease has reached in a particular case. Here the S.R. may be a valuable guide. Many such cases have been followed and it has invariably been found that the first indication that nodules are about to vanish is a gradual return of a high S.R. to normal (see fig. 5). Conversely a persistently raised S.R. is a clear indication that the end of the active phase has not been reached and that the nodules will remain present for an indefinite period. Many cases will continue in this manner for many months, the number of nodules varying from time to time, and the prognosis is left in doubt. Such patients are in a precarious position; many of them ultimately get well but they may suddenly become worse, and, overwhelmed by the increasing number rheumatic lesions, finally succumb (see fig. 6).

\section{Conclusions.}

1. The close relationship between rheumatic activity and the sedimentation rate has been confirmed.

2. Acute tonsillitis and influenza may both cause more than a temporary rise in the sedimentation rate. This must be remembered when making use of the test as possible evidence of active rheumatism. Chronic tonsillar infection on the other hand does not as a rule have any appreciable effect on the sedimentation rate.

3. The influence of anaemia on the sedimentation rate has been examined and a method of assessing the true value of the test in the presence of anaemia is suggested.

4. In acute chorea there is only a small, transient rise of the sedimentation rate. This may even be absent. No indication is given by the sedimentation rate of the possibility of subsequent cardiac involvement.

5. In congestive cardiac failure the sedimentation rate frequently falls to normal even in the presence of active disease. This is a bad prognostic sign.

6. The test is of value in detecting subacute rheumatism and ' miniature rheumatic fever' following tonsillitis.

7. When nodules are present the test has a prognostic significance. Fall of the sedimentation rate heralds their disappearance.

We wish to thank Dr. A. Gordon Signy for some of the S.R. tests which he carried out in the later stages of these investigations. We are extremely grateful to the Matron and Nursing Staff of the Children's Heart Hospital, West Wickham, for their invaluable assistance throughout this work. Our 
thanks are also due to Dr. Nabarro, the Director of the Pathological Department at the Hospital for Sick Children, Great Ormond Street, for his continued interest and encouragement, and to those members of the Honorary Staff who placed their rheumatic cases at our disposal.

\section{REFERENGES.}

1. Bach, F., \& Gray Hill, W., Lancet, London, 1932, i, 75.

2. Hässler, E., \& Möller, L., Jahrb. f. Kinderh., Berlin, 1932, CXXXVI, 257.

3. Payne, W. W., Lancet, London, 1932, i, 74.

4. Perry, C. Bruce, Arch. Dis. Childh., London, 1934, IX, 285.

5. Rourke, M. D., \& Ernstene, A. C., J. Clin. Invest., Lancaster, 1930, VIII, 545.

6. Struthers, R. R., and Bacal, H. L., Canad. Med. Ass. J., Montreal, 1933, XXIX, 470.

7. Walton, A. C. R., Quart. J. Med., Oxford, 1933, II, 79.

8. Warner, E. C., Proc. Roy. Soc. Med., London, 1934, XXVII, 963.

9. Wintrobe, M. M., \& Landsberg, J. W., Am. J. Med. Sci., Philadelph., 1935, CLXXXIX, 102. 